\title{
COMPARATIVE ACTIONS OF GABA AND ACETYLCHOLINE ON THE XENOPUS LAEVIS LATERAL LINE
}

\author{
R. P. Bobbin, ${ }^{*}$ S. C. Bledsoe Jr., $†$ S. Winbery, ${ }^{*}$ G. Ceasar* and G. L. Jenison* \\ "Louisiana State University Medical School, Kresge Hearing Research Laboratory of the South, \\ Department of Otorhinolaryngology and Biocommunication, New Orleans, LA 70119, USA. Telephone: \\ (504) 947-6641 and †Kresge Hearing Research Institute, University of Michigan Medical School, Ann \\ Arbor, MI 48109, USA
}

(Received 2 July 1984)

\begin{abstract}
The effects of GABA, acetylcholine and carbachol on the spontaneous activity of afferent nerve fibers in the lateral line of Xenopus laevis are characterized.

2. Atropine and bicuculline were also tested on drug- and water motion-evoked activity.

3. GABA $(0.019-1.25 \mathrm{mM})$ suppressed and both acetylcholine $(1.25-80 \mu \mathrm{M})$ and carbachol $(1.25-40 \mu \mathrm{M})$ increased spontaneous activity. These actions were blocked by bicuculline $(100 \mu \mathrm{M})$ and atropine $(4 \mu \mathrm{M})$ respectively.

4. Atropine $(20 \mu \mathrm{M})$ and bicuculline $(100 \mu \mathrm{M})$ had no effect on water motion-evoked activity.

5. The results characterize actions of GABA and acetylcholine not previously described and provide evidence that does not support the hypothesis that GABA or acetylcholine are the afferent transmitter.
\end{abstract}

\section{INTRODUCTION}

Gamma-aminobutyric acid (GABA), the $\alpha$-decarboxylation product of $L$-glutamate, is widely accepted as a major inhibitory neurotransmitter in the vertebrate central nervous system. However, in octavolateralis sensory organs, the role of GABA in synaptic processes is unresolved. Based on biochemical findings, Flock and Lam (1974) proposed that GABA might be the excitatory afferent transmitter released by hair cells. Indeed, GABA has been shown to excite afferent nerve fibers in the saccule of the cat (Felix and Ehrenberger, 1982). However, in the mammalian cochlea, amphibian lateral line and amphibian semicircular canal GABA has been reported as having no demonstrable effect (Bobbin and Guth, 1970; Russell, 1976; Klinke and Oertel, 1977; Bobbin and Thompson, 1978; Guth, 1984). Recently, however, we compared GABA to other analogs of L-glutamate in the lateral line of Xenopus laevis, and found GABA to be a powerful inhibitory substance (Bledsoe et al., 1983). To gain further insight into the mechanism of GABA in this hair cell system, we have now studied its actions further and compared them to those of acetylcholine and carbachol, two other compounds reported to be inhibitory in this system (Russell, 1971, 1976) and in the cochlea (Bobbin et al., 1984). Preliminary reports have been presented (Bobbin et al., 1983; Winbery and Bobbin, 1983).

\section{MATERIALS AND METHODS}

Experiments were performed on male and female African clawed frogs (Xenopus laevis). The methods for removing a portion of skin containing the lateral line organ, and isolating a single stitch (cluster of hair cells) were as previously described (Bledsoe et al., 1983; Bledsoe and Bobbin, 1982). The effects of drugs on the spontaneous activity of afferent nerve fibers were studied using the preparation described by Bledsoe et al. (1983). A few modifications were instituted during the study. These in- cluded oxygenating the Ringer solution bathing the serosal surface of the skin. eliminating the glass slide positioned under the skin and instilling water at a flow rate of $0.5 \mathrm{ml} / \mathrm{min}$ under the skin (between the external, cupular surface and the supporting surface). Drugs were dissolved in Ringer solution $\left(\mathrm{NaCl}, 104.5 \mathrm{mM} ; \mathrm{CaCl}_{2}, 1.8 \mathrm{mM} ; \mathrm{KCl}\right.$, $2 \mathrm{mM} ; \mathrm{KCl}, 2 \mathrm{mM} ; \mathrm{NaH}_{2} \mathrm{PO}_{4}, 2.15 \mathrm{mM} ; \quad \mathrm{Na} 2 \mathrm{HPO}_{4}$, $0.85 \mathrm{mM} ; \mathrm{pH} 7$ ) and then applied to the serosal surface of an isolated stitch. The high magnesium-low calcium Ringer was the same except that it contained $10 \mathrm{mM} \mathrm{MgCl}$, and the calcium was lowered $\left(\mathrm{CaCl}_{2}, 0 \mathrm{mM} N=1,0.1 \mathrm{mM} N=7\right)$. Three methods of drug application were used: (1) a $30 \mu \mathrm{l}$ volume of drug solution was applied during a brief interruption in the Ringer wash (Bledsoe et al., 1983); (2) a $1 \mathrm{ml}$ volume of drug solution was injected in to the tube delivering the Ringer wash so that the $1 \mathrm{ml}$ washed over the preparations ( $1 \mathrm{ml} / \mathrm{min})$; and (3) the drug was included in the Ringer wash (Bledsoe and Bobbin, 1982). To evaluate the effects of drugs on water motion-induced responses of afferent nerve fibers, the preparation previously described was used (Bledsoe and Bobbin, 1982). The methods of stimulating an isolated stitch were those used by Harris and Milne (1966). A glass rod attached to the cone of a loudspeaker was placed in the water bathing the external surface of the skin. It was positioned approximately $1 \mathrm{~mm}$ beneath a selected stitch and vibrated at a frequency of $35 \mathrm{~Hz}$ with a sinusoidal voltage. Stimulus magnitude is expressed in $\mathrm{dB}$ relative to the threshold of excitation. Threshold was established with audiovisual cues and defined as the intensity needed to produce a just detectable increase in spontaneous discharge rate. Drug concentrations are expressed in terms of the free base or acid. The effects of drugs were quantified using spike rates expressed in terms of the number of spikes per $30 \mathrm{sec}$ bins.

\section{RESULTS}

GABA depressed afferent spontaneous activity at concentrations as low as $19 \mu \mathrm{M}$ in some preparations. In others, $1.25 \mathrm{mM}$ was required to produce a detectable effect. In sensitive preparations, GABA caused a concentration-dependent depression of spontaneous activity (Fig. 1, a-e). Concentration- 


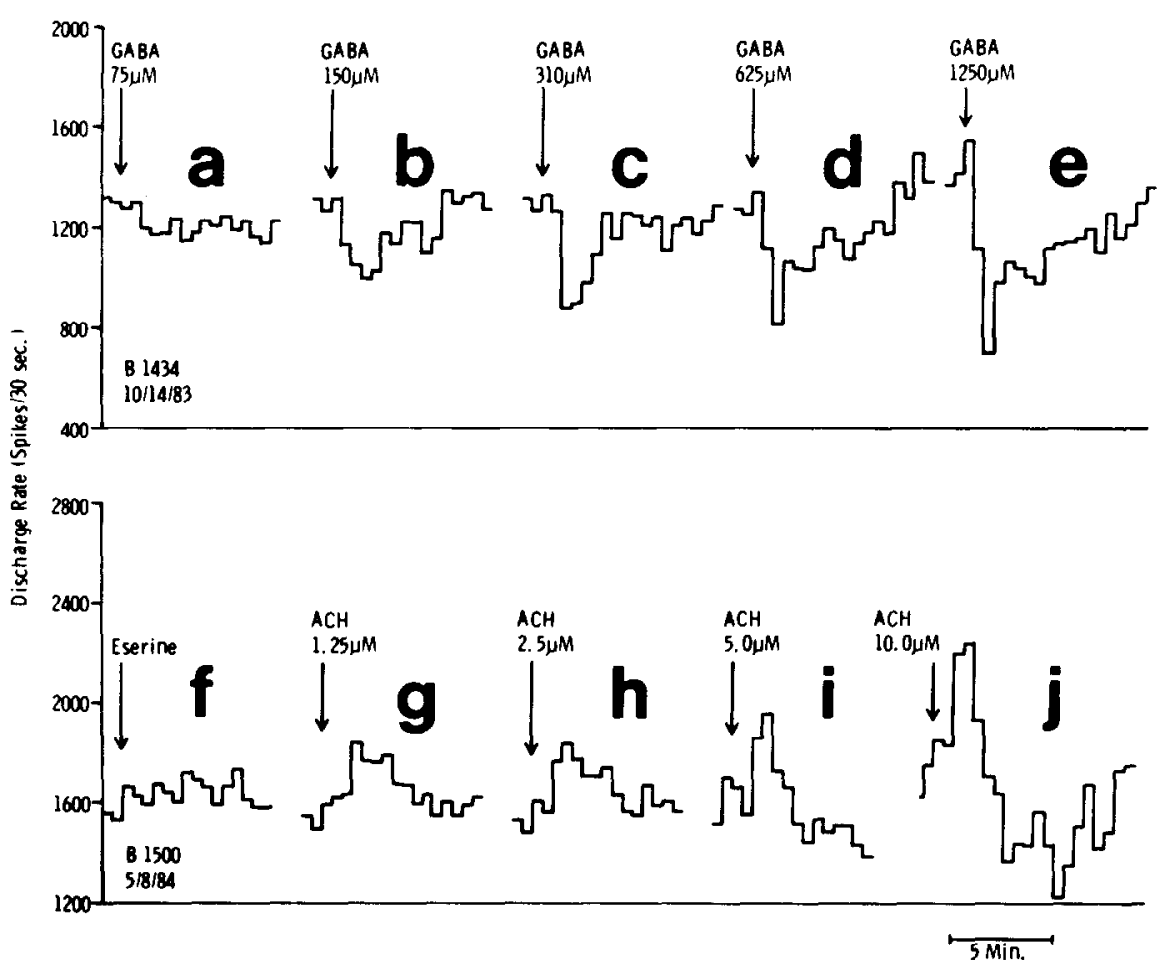

Fig. 1. Lateral line afferent nerve fiber response from two experiments (B1434, a-e; and B1500, $\mathrm{f}-\mathrm{j}$ ) illustrating that $\gamma$-aminobutyric acid (GABA) at $75-1250 \mu \mathrm{M}$ suppressed spontaneous activity whereas acetylcholine $(\mathrm{ACH})$ at $1.25-10 \mu \mathrm{M}$ in the presence of eserine $(5 \mu \mathrm{M})$ increases spontaneous activity. Drugs were applied at the arrows by method 2 (see text), wherein $1 \mathrm{ml}$ of drug was injected into the tube delivering the Ringer wash.

effect curves for GABA $(19-300 \mu \mathrm{M})$ are illustrated in Fig. 2. At maximally effective concentrations, GABA produced a $54 \pm 9 \%$ (mean $\pm \mathrm{SE}, N=6$ ) depression of spontaneous activity. The estimated $E C_{50}$ value (concentration causing $50 \%$ of the maximum response) for GABA was $84 \mu \mathrm{M}$.

Acetylcholine was applied to the stitch in $5 \mu \mathrm{M}$ eserine (physostigmine sulfate). Eserine was also present in the Ringer wash. Both acetylcholine and carbachol caused a concentration-dependent increase of spontaneous activity (Fig. 1, $\mathrm{f}-\mathrm{j}$ ) when applied using all three methods of application. At higher concentrations, a suppression of spontaneous activity began to appear after the increase (Fig. 1, i and j). Like GABA, some skins were more sensitive to these agents than others. Concentration-effect curves for

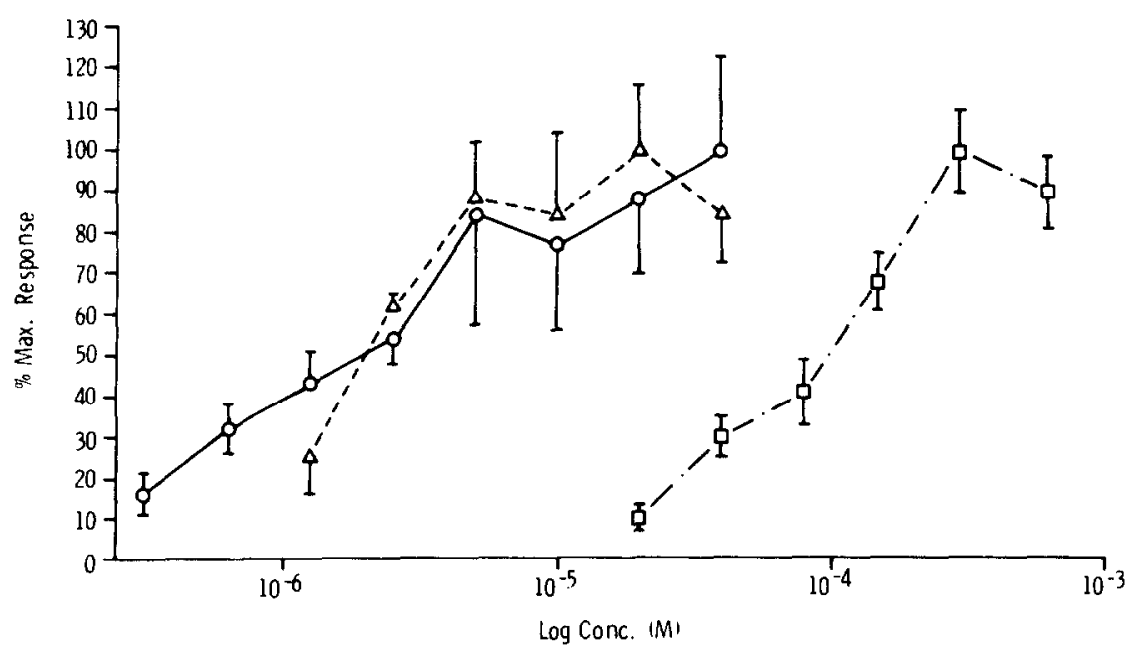

Fig. 2. Log dose-response curves for the excitatory effects of carbachol $(\triangle)$ and aceylcholine $(O)$ in eserine $(5 \mu \mathrm{M})$, and the inhibitory effect of GABA $(\square)$ on spontaneous activity. The data at each concentration is expressed as a percentage of the mean maximal effect produced by each substance. Each point is the mean of four to six determinations in five or six experiments; vertical bars show SE. Drugs were applied as in Fig. 1. 
Table 1. Reduction of responses to GABA, and carbachol, but not L-glutamate induced by the presence of atropine (Atr) or bicuculline (Bic). Represented is the percentage (mean $\pm S E$ ) change from preblocker responses. Numbers in parentheses represent the number of applications. Drugs were applied by the methods described in the text

\begin{tabular}{lcccc}
\hline & GABA & Carbachol & L-Glutamate & \\
& $(0.6-5 \mathrm{mM})$ & $(5-20 \mu \mathrm{M})$ & $(1-2 \mathrm{mM})$ & \\
& $\bar{X} \pm \mathrm{SE}$ & $\bar{X} \pm \mathrm{SE}$ & $\bar{X} \pm \mathrm{SE}$ & SPONT \\
\hline Atr: $4 \mu \mathrm{M}$ & $+11 \pm 5(3)$ & $-80 \pm 3(5)$ & $-1 \pm 16(4)$ & $-29 \pm 8(5)$ \\
Bic: $100 \mu \mathrm{M}$ & $-78 \pm 7(8)$ & $-11 \pm 20(5)$ & $+36 \pm 21(4)$ & $-25 \pm 13(8)$ \\
\hline
\end{tabular}

the increase in spontaneous activity to acetylcholine and carbachol are illustrated in Fig. 2. At maximally effective concentrations, acetylcholine produced a $48 \pm 7 \%$ (mean $\pm \mathrm{SE}, N=4$ ) increase and carbachol a $3 \overline{7} \pm 5 \%$ (mean $\pm \mathrm{SE}, N=5$ ) increase in spontaneous activity. The estimated $E C_{50}$ value for the excitation to acetylcholine and carbachol was $2 \mu \mathrm{M}$ for both.

The effect of the acetylcholine antagonist, atropine sulfate, and the GABA antagonist, bicuculline methiodide, were tested on responses to the agonists and water motion-evoked activity. Because of the difficulties associated with the use of eserine, carbachol was utilized in most of these experiments. Acetylcholine plus eserine was tested in only two experiments. The results were comparable to those obtained with carbachol. Bicuculline $(100 \mu \mathrm{M})$ blocked the response to GABA but had little effect on the actions of carbachol or L-glutamate (Table 1).
Carbachol was blocked by atropine $(4 \mu \mathrm{M})$ which had little effect on the responses to GABA or L-glutamate (Table 1). A reduction in spontaneous activity was observed with both blockers. In a total of seven experiments, water motion-induced activity was unaffected by equal or greater concentrations of atropine and bicuculline that blocked their respective agonist (Fig. 3).

In two experiments a high magnesium-low calcium Ringer solution reversibly abolished both spontaneous and water motion-induced activity (Fig. 4A). In six other experiments high magnesium-low calcium Ringer abolished spontaneous activity, and the responses to carbachol $(10-40 \mu \mathrm{M}, N=4)$, acetylcholine $(10 \mu \mathrm{M}, N=1)$, and $N$-methyl-D-aspartate $(1 \mathrm{mM}, \quad N=2)$. The results with L-glutamate (1-2 $\mathrm{mM}, N=5$ ) vary with the way the data is expressed. Responses were reduced by the high magnesium-low calcium Ringer if maximal or abso-

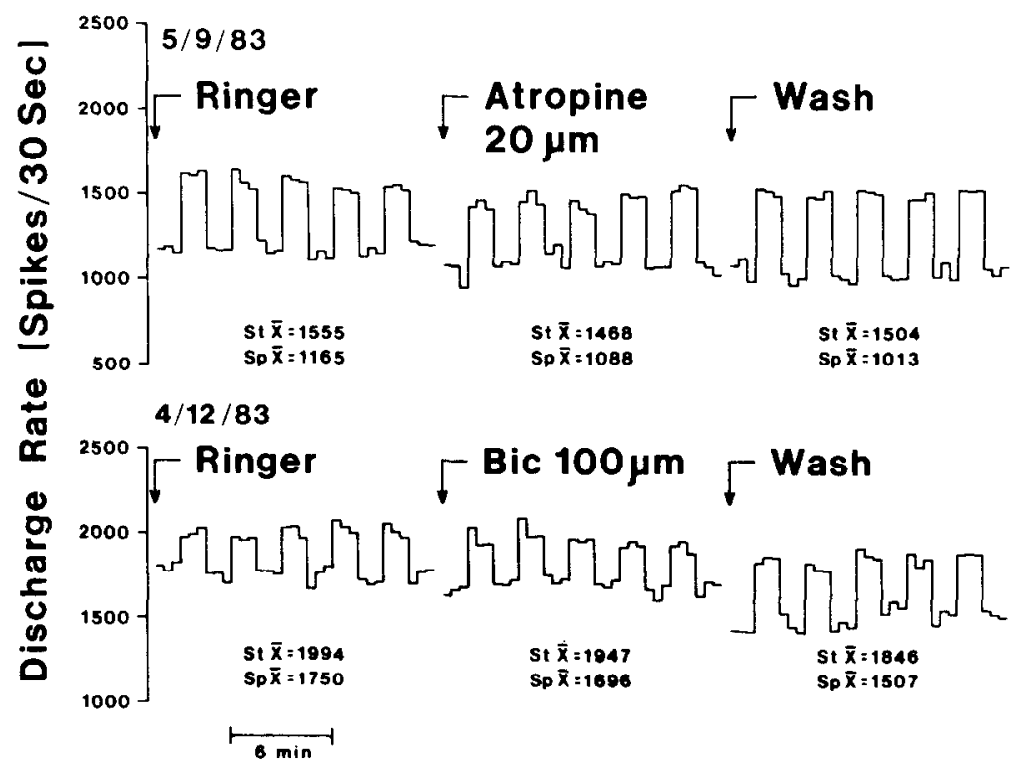

Fig. 3. Lack of effect on spontaneous activity and water motion-induced excitation of afferent nerve fibers in the Xenopus lateral line by $20 \mu \mathrm{M}$ atropine and $100 \mu \mathrm{M}$ bicuculline. At the arrows designated "Ringer" the drug-free Ringer wash was turned off and the remaining fluid on the serosal surface of the skin rapidly exchanged for a $500 \mu \mathrm{l}$ volume of fresh drug-free Ringer. An initial $90 \mathrm{sec}$ of spontaneous activity followed by five $90 \mathrm{sec}$ periods of stimulated and spontaneous activity were recorded in $30 \mathrm{sec}$ time bins. The data following the arrows designated "Atropine" and "Bic" were obtained by repeating the stimulatedspontaneous sampling sequence $36.5 \mathrm{~min}$ after the $500 \mu \mathrm{l}$ of Ringer in the chamber was exchanged for $500 \mu \mathrm{l}$ of Ringer containing $20 \mu \mathrm{M}$ atropine or $100 \mu \mathrm{M}$ bicuculline, respectively. The data at the arrows designated "Wash" were recorded $30 \mathrm{~min}$ after the preparations were washed with drug-free Ringer to remove drugs. Stimulus intensity was 10 and $5 \mathrm{~dB}$ (re threshold) for $5 / 9 / 83$ and $4 / 12 / 83$, respectively. Mean discharge-rate values (spikes/30 sec) for the stimulated $(\mathrm{St})$ and spontaneous $(\mathrm{Sp}$ ) conditions obtained in each of the solutions are given. They were calculated from the second and third 30-sec time bins in each of the last four samples of spontaneous and stimulated activity. 


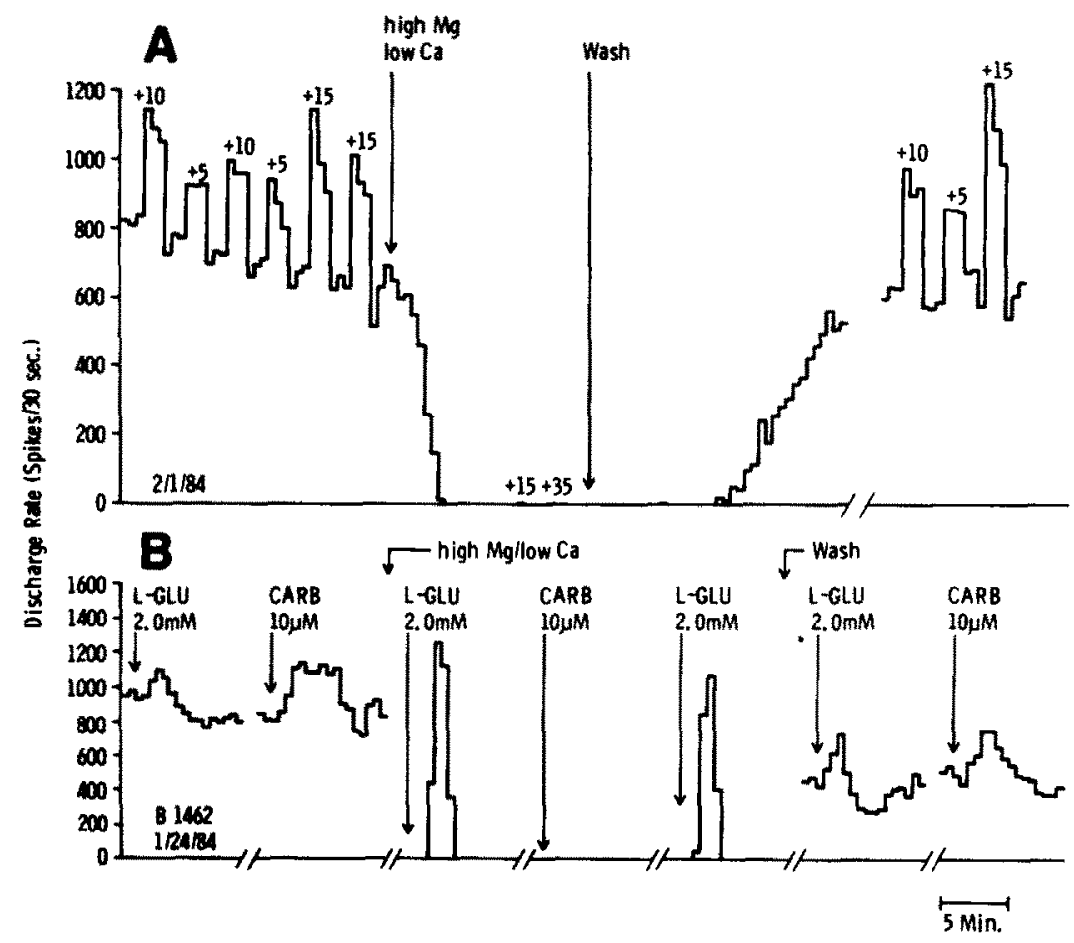

Fig. 4.(A) Suppression of spontaneous activity and water motion-induced excitation of afferent nerve fibers in the Xenopus lateral line by high magnesium-low calcium solution $\left(\mathrm{MgCl}_{2}, 10 \mathrm{mM}, \mathrm{CaCl}_{2}\right.$, $0.1 \mathrm{mM}$ ). Methods as in Fig. 3 except that the water motion was presented at three intensity levels, +5 , +10 and $+15 \mathrm{~dB}$ (re threshold). Note that during the magnesium block a stimulus even at $35 \mathrm{~dB}$ above threshold failed to elicit an excitatory response. (B) Effects of L-glutamate (L-GLU), and carbachol (CARB) in the presence of drug-free Ringer solution and high magnesium-low calcium solution (as above in A) on only the spontaneous activity of lateral line afferent fibers.

lute discharge rates in the presence of L-glutamate were averaged across skins (in normal Ringer before magnesium: $1128 \pm 162$ spikes $/ 30 \mathrm{sec}$, mean $\pm \mathrm{SE}$; during high magnesium: $886 \pm 306$ spikes $/ 30 \mathrm{sec}$, mean $\pm \mathrm{SE}$ ). On the other hand, if expressed as the differences between the pre-glutamate spontaneous rates and maximal discharge rates during glutamate (before the high magnesium: $299 \pm 73 \mathrm{spikes} / 30 \mathrm{sec}$, mean $\pm \mathrm{SE}$; and during the high magnesium: $746 \pm 304$ spikes/ $30 \mathrm{sec}$, mean $\pm \mathrm{SE}$ ), then the responses were enhanced. Figure $4 \mathrm{~B}$ illustrates an example where the response to L-glutamate was probably enhanced by the high magnesium-low calcium, but the response to carbachol was abolished.

\section{DISCUSSION}

The suppressive actions of GABA we have observed and the selective antagonism of these actions by bicuculline suggest that GABA receptors are present in this hair cell system. However, the functional significance of these receptors is not clear.

Studying the synthesis of GABA in several hair cell organs, Flock and Lam (1974) proposed that GABA might be the afferent transmitter since it was synthesized from L-glutamate both in systems which contained efferents and those that did not. However, the only neurophysiological evidence for this suggestion are the results of Felix and Ehrenberger (1982) which demonstrate an excitation by GABA in the saccule of the cat. Instead, the hypothesis has not generally been accepted since no effect of GABA has been demonstrated in the cochlea of cat (Bobbin and Guth, 1970) and guinea pig (Klinke and Oertel, 1977; Bohbin and Thompson, 1978). The suppressive actions of GABA that we observed and the fact that bicuculline had little effect on excitation induced by water motion also suggest that GABA is not the afferent transmitter. Recently, though, uptake of GABA has been found in the efferents of the cochlea (Schwartz and Ryan, 1983) and the release of a GABA-like substance has been found to correlate with sound exposure in guinea pig perilymph (Drescher et al., 1983). Overall, it seems additional research is needed to define the role of GABA in octavolateralis systems.

The increase in spontaneous activity produced by acetylcholine and carbachol is not entirely in contrast to the results obtained by Russell (1971). For we do confirm the suppression reported by Russell, but in addition, we observe an augmentation of spontaneous activity before the suppression occurs. The reason for the discrepancy currently eludes us, although it should be noted that there is a suggestion of an increase in Russell's data (see Fig. 1, p. 646; and Fig. 5, p. 647, Russell, 1971). The suppression is similar to that occurring with the excitatory amino acids (Bledsoe et al., 1983). Both appear at concentrations higher than needed to produce an excitatory response, and after the excitation has taken place. This may indicate that both responses result from a similar mechanism such as depolarization followed 
by depolarization block. On the other hand, the mechanisms are most probably different, since the amino acid effect seems to be due to a postsynaptic action, and the cholinergic effect to a presynaptic one (see below).

The increase in spontaneous activity produced by carbachol was selectively blocked by atropine. Thus, it seems that the excitation results from activation of a specific cholinergic receptor. This receptor does not appear to be the one activated by the afferent transmitter because atropine did not affect water motioninduced activity. In most systems, magnesium ions are known to compete with calcium presynaptically and thus prevent the release of transmitter and act like calcium postsynaptically to stabilize the neuronal membrane (see Rubin, 1970). Magnesium suppressed spontaneous activity and the response to natural stimulation, acetylcholine and carbachol. The block of spontaneous activity and the response to natural stimulation indicates that both are due to the release of transmitter presynaptically. In addition, because of the block by magnesium, it appears that the increase in activity produced by carbachol and acetylcholine occurred by a presynaptic action on the hair cells which caused the release of the afferent transmitter. That the magnesium block was not due to excessive stabilization of the postsynaptic membrane is indicated by the remaining response to an equipotent concentration of L-glutamate.

Acetylcholine appears to be the transmitter of the efferent fibers in acousticolateralis systems. Electrical stimulation of efferents in the Xenopus lateral line has been reported to suppress afferent activity (Russell, 1968, 1971, 1976). In general this has been the case in other systems such as the burbot lateral line (Flock and Russell, 1973), the turtle (Art et al., 1982) and mammalian cochleae (Wiederhold and Kiang, 1970). The exception seems to be efferents to the vestibular apparatus which increase the discharge rate of vestibular afferents (Goldberg and Fernandez, 1980) and where carbachol and acetylcholine are excitatory (Guth, 1984). In addition, two unusual instances where efferent stimulation increased the fring of afferents have been reported. One was in burbot where after the administration of gallamine, efferent stimulation no longer suppressed but enhanced afferent discharge rate (Flock and Russell, 1973). The other was in turtle hair cells where intracellular injection of hyperpolarizing current reversed the hyperpolarization of the hair cell evoked by efferent stimulation and revealed an early depolarization (Art et al., 1982). These last two studies suggest that the increase in afferent activity we observed with acetylcholine and carbachol may be due to an action at a similar site, the actions of which are not readily seen upon efferent stimulation. Whether this site has a physiological role remains to be determined.

The excitation to L-glutamate in the presence of high magnesium is evidence that $\mathrm{L}$-glutamate exerts a portion of its action directly on the postsynaptic afferent nerve fibers. There appear to be at least three types of receptors for excitatory amino acids: kainate, quisqualate and $N$-methyl-D-aspartate (NMDA). Since all three agonists, NMDA, kainate and quisqualate, activate the lateral line (Bledsoe et al., 1983) and their receptors may be activated by L-glutamate, then a portion of the response to L-glutamate in the lateral line is probably due to activation of these receptors. It has been reported that magnesium ions, even in small concentrations, block the NMDA receptor, but not the kainate or quisqualate receptors in other systems (Ault et al., 1980; Smith, 1982). Thus, the block of NMDA we observed with high magnesium was expected. It follows that the portion of the L-glutamate response due to activation of NMDA receptors should be blocked by the high magnesium and this should have caused a suppression of the response to L-glutamate. Instead, it seems the response to L-glutamate may have been potentiated by the high magnesium. A potentiation of the response to L-glutamate by divalent cations such as magnesium has been reported in other systems (Smith, 1982). This may occur by an action at the remaining kainate and quisqualate receptors. In addition, it has been reported that certain divalent cations, including magnesium, enhance the binding of L-glutamate to what are believed to be postsynaptic receptor sites in hippocampal membrane preparations (Baudry and Lynch, 1979).

In conclusion, the results introduce and define new actions by two compounds in the Xenopus lateral line: a suppression by GABA and an excitation by acetylcholine. They also add additional evidence that the lateral line is different from the cochlea of mammals. Previously, it was shown that NMDA receptors are present and blocked by $D-\alpha$-aminoadipate in the lateral line and appear to be the receptors activated by the afferent transmitter, possibly L-glutamate (Bledsoe and Bobbin, 1982; Bobbin et al., 1984). Also it was shown that NMDA is not active in the cochlea of guinea pig (Jenison and Bobbin, 1983), and aminoadipate is inactive in the cochlea of cat (Fex and Martin, 1980) and guinea pig (Bobbin et al., 1984). We have now extended the number of differences to include a response to GABA in the lateral line but not in the cochlea, and an apparent excitatory response to acetylcholine in the lateral line which is followed by a suppression of activity whereas only suppression has been detected to date in the cochlea. These resuits further emphasize the fact that the synaptic chemistry of various octavolateralis organs is probably different.

Acknowledgements - Thanks to Anthony Florez for electrical engineering and Cindy Frazier and Vibha Flax for their aid in the preparation of this manuscript. This work was supported at Kresge New Orleans by Reasearch Grant USPHS NS-16080 and Training Grant USPHS NS-07058 and at Kresge Michigan by Program Project Grant USPHS NS-05785 and a grant from the University of Michigan.

\section{REFERENCES}

Art J., Crawford A. C., Fettiplace R. and Fuchs P. A. (1982) Efferent regulation of hair cells in the turtle cochlea. Proc. R. Soc. B216, 377-384.

Ault B., Evans R. H., Francis A. A., Oakes D. J. and Watkins J. C. (1980) Selective depression of excitatory amino acid induced depolarizations by magnesium ions in isolated spinal cord preparations. J. Physiol., Lond. 307, $413-428$ 
Baudry M. and Lynch G. (1979) Regulation of glutamate receptors by cations. Nature, Lond. 282, 748-750.

Bledsoe S. C. Jr. and Bobbin R. P. (1982) Effects of $D-\alpha$-aminoadipate on excitation of afferent fibers in the lateral line of Xenopus laevis. Neurosci. Lett. 32, 315-320.

Bledsoe S. C. Jr., Chihal D. M., Bobbin R. P. and Morgan D. M. (1983) Comparative actions of glutamate and related substances on the lateral line of Xenopus laevis. Comp. Biochem. Physiol. 75C, 119-206.

Bobbin R. P. and Guth P. S. (1970) Evidence that gammaaminobutyric acid is not the inhibitory transmitter at the crossed olivo-cochlear nerve-hair cell junction. Neuropharmacology 9, 567-574.

Bobbin R. P. and Thompson M. H. (1978) Effects of putative transmitter on afferent cochlear transmission. Ann. Otol. Rhinol. Lar. 87, 185-190.

Bobbin R. P., Bledsoe S. C. Jr, Jenison G. L., Winbery S. and Ceasar G. (1983) Actions of atropine and bicuculline on the activity of afferent fibers in the Xenopus laevis lateral line. Neurosci. Abs. 9, 739.

Bobbin R. P., Bledsoe S. C. Jr. and Jenison G. L. (1984) Neurotransmitters of the cochlea and lateral line organ. In Hearing Science: Recent Advances (Edited by Berlin C. I.), pp. 159-180. College Hill Press, San Diego.

Drescher M. J., Drescher D. G. and Medina J. E. (1983) Effect of sound stimulation at several levels on concentrations of primary amines, including neurotransmitter candidates, in perilymph of the guinea pig inner ear. $J$. Neurochem. 41, 309-320.

Fex J. and Martin M. R. (1980) Lack of effect of DL- $x$-aminoadipate, an excitatory amino acid antagonist, on cat auditory nerve responses to sound. Neuropharmacology 19, 809-811.

Felix D. and Ehrenberger K. (1982) The action of putative neurotransmitter substances in the cat labyrinth. Acta otolaryngol. 93, 101-105.

Flock A. and Lam D. M. K. (1974) Neurotransmitter synthesis in inner ear and lateral line sense organs. Nature, Lond. 249, 142-144.

Flock A. and Russell I. I. (1973) The post-synaptic action of efferent fibres in the lateral line organ of the burbot Lota lota. J. Physiol., Lond. 235, 591-605.

Goldberg J. M. and Fernandez C. (1980) Efferent vestibular system in the squirrel monkey: anatomical location and influence on afferent activity. $J$. Neurophysiol. 43, 986-1025.

Guth S. L. (1984) Single unit responses from the isolated posterior semicircular canal of the bullfrog (Rana catesbeiana) in the study of vestibular pharmacology. Dissertation, Tulane University, New Orleans, LA, USA.

Harris G. G. and Milne D. C. (1966) Input output characteristics of the lateral-line sense organ of Xenopus laevis. J. Acoust. Soc. Am. 40, 32-42.

Jenison G. L. and Bobbin R. P. (1983) Effects of quisqualate on guinea pig cochlear potentials. Association for $R e$ search in Otolaryngology, Abstracts. St. Petersburg Beach, Florida, 23-27 January.

Klinke R. and Oertel W. (1977) Evidence that GABA is not the afferent transmitter in the cochlea. Expl Brain Res. 28, $31 \mathrm{l}-314$.

Rubin R. P. (1970) The role of calcium in the release of neurotransmitter substances and hormones. Pharmac. Rev. 22, 389-428.

Russell I. J. (1968) Influence of efferent fibres on a receptor. Nature, Lond. 219, 177-178.

Russell I. J. (1971) The pharmacology of efferent synapses in the lateral line system of Xenopus laevis. J. exp. Biol. 54, 643-658.

Russell I. J. (1976) Amphibian lateral line receptors. In Frog Neurobiology, A Handbook (Edited by Llinas R. and Precht W.), pp. 513-550. Springer, New York.

Schwartz I. R. and Ryan A. F. (1983) Differential labeling of sensory cell and neural populations in the organ of Corti following amino acid incubations. Hearing Res. 9, 185-200.

Smith P. A. (1982) The use of low concentrations of divalent cations to demonstrate a role for $N$-methyl-D-aspartate receptors in synaptic transmission in amphibian spinal cord. Br. J. Pharmac. 77, 363-373.

Wiederhold M. L. and Kiang N. Y.-S. (1970) Effects of electric stimulation of the crossed olivocochlear bundle on single auditory nerve fibres in the cat. J. Acoust. Soc. Am. 48, 951-965.

Winbery S. L. and Bobbin R. P. (1983) Actions of acetylcholine and carbachol on the spontaneous activity of afferent fibers in the Xenopus laevis lateral line. Association for Research in Otolaryngology, Abstracts, p. 47. St. Petersburg Beach, Florida, 23-27 January. 